\title{
Batch Sorption Experiments: Langmuir and Freundlich Isotherm Studies for the Adsorption of Textile Metal Ions onto Teff Straw (Eragrostis tef) Agricultural Waste
}

\author{
Mulu Berhe Desta \\ Department of Chemistry, College of Natural and Computational Sciences, Mekelle University, P.O. Box 231, Mekelle, Ethiopia \\ Correspondence should be addressed to Mulu Berhe Desta; muller.desta@yahoo.com
}

Received 20 February 2013; Accepted 2 August 2013

Academic Editor: Angelo Lucia

Copyright (c) 2013 Mulu Berhe Desta. This is an open access article distributed under the Creative Commons Attribution License, which permits unrestricted use, distribution, and reproduction in any medium, provided the original work is properly cited.

Adsorption of heavy metals $(\mathrm{Cr}, \mathrm{Cd}, \mathrm{Pb}, \mathrm{Ni}$, and $\mathrm{Cu}$ ) onto Activated Teff Straw (ATS) has been studied using batch-adsorption techniques. This study was carried out to examine the adsorption capacity of the low-cost adsorbent ATS for the removal of heavy metals from textile effluents. The influence of contact time, $\mathrm{pH}$, Temperature, and adsorbent dose on the adsorption process was also studied. Results revealed that adsorption rate initially increased rapidly, and the optimal removal efficiency was reached within about 1 hour. Further increase in contact time did not show significant change in equilibrium concentration; that is, the adsorption phase reached equilibrium. The adsorption isotherms could be fitted well by the Langmuir model. The $R_{L}$ value in the present investigation was less than one, indicating that the adsorption of the metal ion onto ATS is favorable. After treatment with ATS the levels of heavy metals were observed to decrease by $88 \%(\mathrm{Ni}), 82.9 \%(\mathrm{Cd}), 81.5 \%(\mathrm{Cu}), 74.5 \%(\mathrm{Cr})$, and $68.9 \%(\mathrm{~Pb})$. Results indicate that the freely abundant, locally available, low-cost adsorbent, Teff straw can be treated as economically viable for the removal of metal ions from textile effluents.

\section{Introduction}

Demands of clothing and apparel increase with the improving sense of fashion and lifestyle; thus textiles are manufactured to meet the growing demands. In developing countries such as Ethiopia, textile production becomes their source of income that contributes to their gross domestic product (GDP). However, this has brought both consequences to such countries either in a positive way which is an improvement of economy or in a negative way which led to an increased anthropogenic impact on the biosphere.

Heavy metals, particularly, $\mathrm{Pb}, \mathrm{Cr}, \mathrm{Cd}$, and $\mathrm{Cu}$ are widely used for the production of color pigments of textile dyes. These heavy metals which have transferred to the environment are highly toxic and can bioaccumulate in the human body aquatic life and natural water bodies and also possibly get trapped in the soil [1]. These toxic heavy metals entering in the aquatic environment are adsorbed onto particulate matter, although they can form free metal ions and soluble complexes that are available for uptake by biological organisms [2].

Various methods of treating effluents containing heavy metals have been developed over years, such as chemical precipitation, chemical oxidation or reduction, electrochemical treatment, ion exchange, reverse osmosis, filtration, evaporation recovery, and electrocoagulation [3-11]. These methods have significant disadvantages, including high energy requirements, inefficient metal removal, generation of toxic sludge, and expensive equipment. Therefore, there is a need to develop an efficient, rapid, cost-effectively and environment friendly method for the removal of heavy metals from effluents. Adsorption of heavy metals is a new technology for treatment of textile effluents containing different types of heavy metals. Adsorption is the adhesion of a chemical substance (adsorbate) onto the surface of a solid (adsorbent). The most widely used adsorbent is activated carbon [12]. The adsorption process is being widely used by various researchers for the removal of heavy metals [13-18] from 


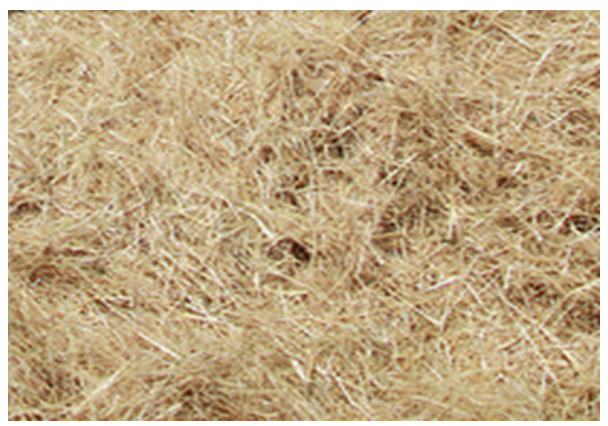

(a)

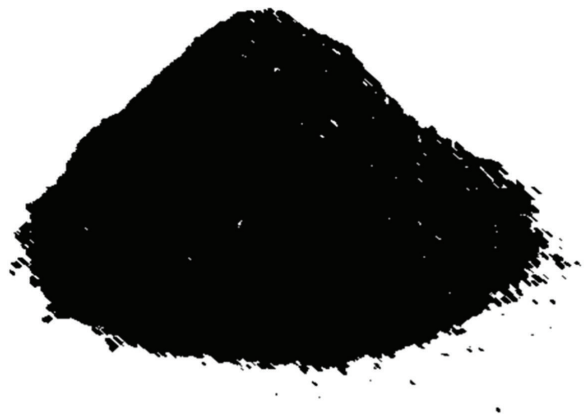

(b)

FIgURE 1: Teff straw before treatment (a) and after treatment (b).

waste streams, and activated carbon has been frequently used as an adsorbent.

Adsorption isotherm is an empirical relationship used to predict how much solute can be adsorbed by activated carbon [19]. Adsorption isotherm is defined as a graphical representation showing the relationship between the amount adsorbed by a unit weight of adsorbent (e.g., activated carbon) and the amount of adsorbate remaining in a test medium at equilibrium, and it shows the distribution of adsorbable solute between the liquid and solid phases at various equilibrium concentrations [20]. The three wellknown isotherms are (a) Freundlich, (b) Langmuir, and (c) BET adsorption isotherm [19].

In this study a new, environment friendly, cost-effective, and locally available agrowaste Eragrostis tef adsorbent was investigated for the adsorption of heavy metals $(\mathrm{Cr}, \mathrm{Cd}, \mathrm{Pb}$, $\mathrm{Ni}$, and $\mathrm{Cu}$ ) from textile effluents. The effects of different parameters such as the $\mathrm{pH}$, the initial metal concentration, the dose of the adsorption, the contact time, and temperature were studied.

\section{Materials and Methods}

2.1. Description of the Study Area. The study was carried at the MAA Garment and Textile Factory built near Alula Abanega airport, due southeast of Mekelle city, Tigray, Northern Ethiopia. The study area lies between latitudes $13^{\circ} 28^{\prime} 56^{\prime \prime} \mathrm{N}$ longitudes $39^{\circ} 31^{\prime} 59^{\prime \prime} \mathrm{E}$. The factory is owned by Kebire Enterprises Plc. and is fully equipped with state-of-art production facilities acquired from the most reputable manufacturers of the world with over 825 sewing machines. The industrial area is spread over $210,000 \mathrm{~m}^{2}$ of land and it utilizes about $24,000 \mathrm{~m}^{3} /$ day fresh water. The effluent discharge amounts to about $13,050 \mathrm{~m}^{3} /$ day, that is, $54.4 \%$ of the total industrial effluents.

2.2. Adsorbent. Teff straw was used as biomass sample in this study for adsorption of heavy metals from textile effluents. Teff (Eragrostis tef) is obviously one of Ethiopia's most important cereal crops. It is indigenous to the country, and it is a fundamental part of the culture, tradition, and food. Recently, the taxonomy of Teff has been clarified by numerical taxonomy techniques, cytology, and biochemistry, including leaf flavonoids and seed protein electrophoretic patterns [2123]. The Teff straw was provided by Mekelle University College of Agriculture and treated in the Physical Chemistry laboratory. Figure 1 shows some samples of Teff straw before treatment and after treatment.

2.3. Sorbent Preparation. Teff straw was washed several times with double-distilled water to remove all dirt in its original particle size followed by filtration and was dried at $100^{\circ} \mathrm{C}$. The cleaned and dried Teff straw was oven-dried at $400^{\circ} \mathrm{C}$ for three hours to form carbonized Teff straw (CTS). The CTS was treated with $1 \mathrm{M}$ sulfuric acid at room temperature. Acidified Teff Straw was dried overnight at $70^{\circ} \mathrm{C}$ and the dried Teff straw was heated to $120^{\circ} \mathrm{C}$. The reacted product was washed repeatedly with distilled water. Finally the cleaned Teff straw was oven-dried overnight at $100^{\circ} \mathrm{C}$ and packed for utilization.

\subsection{Sorption Studies}

2.4.1. Batch Experiments and Adsorption Isotherms. Sorption studies were conducted by the batch technique and column test using wastewater from MAA Garment. Batch experiments were carried out to determine the adsorption isotherms of metal ions onto the adsorbents in $250 \mathrm{~mL}$ glass flask. The flasks were shaken at a constant rate, allowing sufficient time for adsorption equilibrium. It was assumed that the applied shaking speed allows all the surface area to come in contact with heavy metal ions over the course of the experiments. The study was performed at room temperature to be representative of environmentally relevant condition. All experiments were carried out in duplicate and the average value was used for further calculation. The $\mathrm{pH}$ of the solution was measured with a HACH-pH meter. The flasks were plugged and kept closed to avoid the fluctuation of $\mathrm{pH}$ due to the exchange of gases during the experiment. The effects of various parameters on the rate of adsorption process were observed by varying contact time, adsorbent concentration, temperature, and $\mathrm{pH}$ of the solution. The solution volume $(V)$ was kept constant. The amount of metal adsorbed per unit mass is calculated as

$$
Q_{e}=\frac{\left(C_{i}-C_{e}\right) V}{m}
$$


TABLE 1: Mean concentration (mg/L) with St. dev. of HMs in MAA Garment and Textile Factory effluents.

\begin{tabular}{lcccccc}
\hline Sample & Parameters & $\mathrm{Ni}$ & $\mathrm{Cu}$ & $\mathrm{Cd}$ & $\mathrm{Cr}$ & $\mathrm{Pb}$ \\
\hline Untreated & Mean \pm St. dev. & $3.53 \pm 0.33$ & $2.54 \pm 0.74$ & $1.23 \pm 0.22$ & $0.98 \pm 0.07$ & $0.12 \pm 0.02$ \\
Treated & Mean \pm St. dev. & $0.43 \pm 0.19$ & $0.47 \pm 0.12$ & $0.02 \pm 0.01$ & $0.25 \pm 0.05$ & $0.04 \pm 0.01$ \\
\multicolumn{1}{c}{ Percentage removed } & $88 \%$ & $81.5 \%$ & $82.9 \%$ & $74.5 \%$ & $68.9 \%$ \\
\hline
\end{tabular}

where $C_{i}$ and $C_{e}$ are the initial and equilibrium concentration $(\mathrm{mg} / \mathrm{L}), m$ is the mass of the adsorbent $(\mathrm{g})$ and $V$ is the volume of the solution $(\mathrm{mL})$. Percent metal ion removal (\%MR) was calculated using the equation

$$
\% \mathrm{MR}=\frac{\left(C_{i}-C_{e}\right)}{C_{i}} * 100
$$

2.4.2. Column Test. The adsorption experiments were carried out in columns that were equipped with a stopper for controlling the column flow rate. This experiment is useful in understanding and predicting the behavior of the process. The sample solution was passed through the adsorption column with a known amount of ATS at a flow rate of $6 \mathrm{~mL} / \mathrm{min}$ by gravity. The flow rate was kept constant by controlling the stopper valve.

The concentration of residual individual heavy metal in the sorption medium was determined using fully automated PC-controlled true double-beam AAS with fast sequential operation (Varian AA50 FS, Australia) for fast multielement flame AA determinations with features 4 lamp positions and automatic lamp selection. Statistical analysis was performed using the statistical software packages. Detection limits for each metal on the instrument are: $\mathrm{Cr}: 0.006 \mathrm{mg} / \mathrm{Kg}$, Cd: $0.002 \mathrm{mg} / \mathrm{Kg}, \mathrm{Pb}: 0.010 \mathrm{mg} / \mathrm{Kg}$, $\mathrm{Ni}: 0.010 \mathrm{mg} / \mathrm{Kg}$, and $\mathrm{Cu}$ : $0.003 \mathrm{mg} / \mathrm{Kg}$.

\section{Results and Discussion}

3.1. Adsorption of the Tested Heavy Metals onto ATS. Concentrations of heavy metals of the factory's effluent are presented in Table 1. Nickel concentration in the wastewater sample constituted the major portion of the total metal ions determined (3.53) followed by $\mathrm{Cu}(2.54)$ and $\mathrm{Cd}$ (1.23), while $\mathrm{Cr}(0.98)$ and $\mathrm{Pb}(0.12)$ concentrations were the lowest. The concentration of nickel in untreated effluent was found to be $3.53 \pm 0.33$ and in treated sample was $0.43 \pm 0.19$; it was $88 \%$ less as compared to untreated effluent (Table 1). The level of copper was $2.54 \pm 0.74$ in untreated samples and $0.47 \pm 0.12$ in treated samples which means $81.5 \%$ less in treated sample. And the concentrations of cadmium before and after treatment were found to be $1.23 \pm 0.22$ and $0.02 \pm$ 0.01 respectively, while the levels of the concentration of $\mathrm{Pb}$, $0.12 \pm 0.02$ and $0.04 \pm 0.01$. The obtained results revealed that ATS has good adsorption capacity and is effective for the removal of heavy metals from textile effluent.

3.2. Effect of Adsorbent Dose on Adsorption. The effect of adsorbent dose on the adsorption of the heavy metals onto ATS was investigated. The concentration of heavy metals in

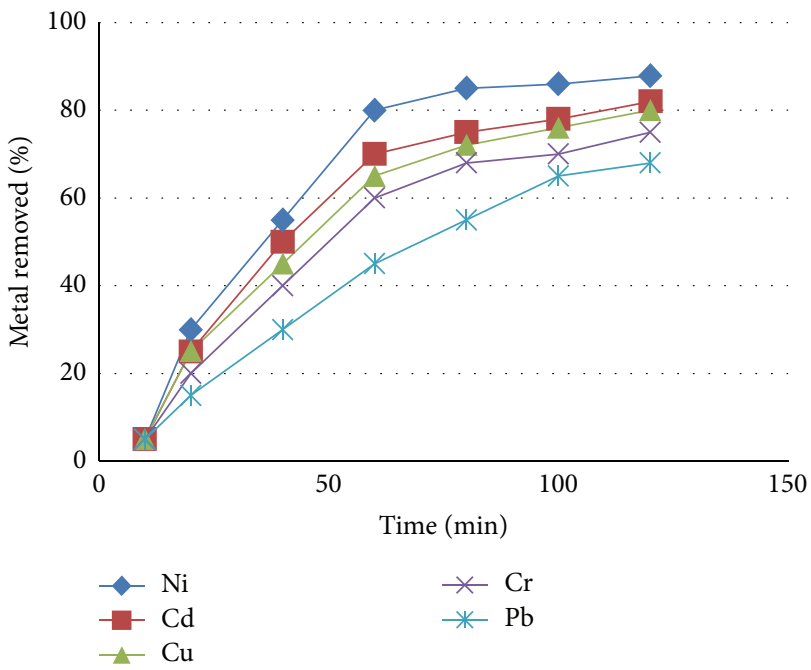

FIGURE 2: Effect of contact time on adsorption efficiency.

the textile effluent was reduced by $88 \%(\mathrm{Ni}), 82.9 \%(\mathrm{Cd})$, $81.5 \%(\mathrm{Cu}), 74.5 \%(\mathrm{Cr})$, and $68.9 \%(\mathrm{~Pb})$ after treatment. Metals adsorption efficiency was increased with increase in adsorbent dose. This revealed that the adsorption sites remain unsaturated during the adsorption reaction whereas the number of sites available for adsorption site increases by increasing the adsorbent dose.

3.3. Effect of Contact Time on Adsorption. The effect of contact time on the adsorption of metal was investigated. Figure 2 shows the percent metal ion removal with respect to time. Contact time is one of the most effective factors in batch adsorption process. Adsorption rate initially increased rapidly, and the optimal removal efficiency was reached within about $60 \mathrm{~min}$. Further increase in contact time did not show significant change in equilibrium concentration; that is, the adsorption phase reached equilibrium.

3.4. Effect of Temperature on Adsorption. Effect of temperature on adsorption of the heavy metals onto ATS was studied by conducting different sets of experiments at different temperatures, that is, $298,308,318,328$, and $343^{\circ} \mathrm{K}$. It was observed that adsorption of metal ions increases with the increase in the temperature.

3.5. Effect of $\mathrm{pH}$ on Adsorption. The $\mathrm{pH}$ of a solution is an important parameter in the adsorption process. During this study, results revealed that the removal of metal ions was strongly dependent on the $\mathrm{pH}$ of the solution. The effect of $\mathrm{pH}$ on adsorption of metal ions onto ATS was studied at 


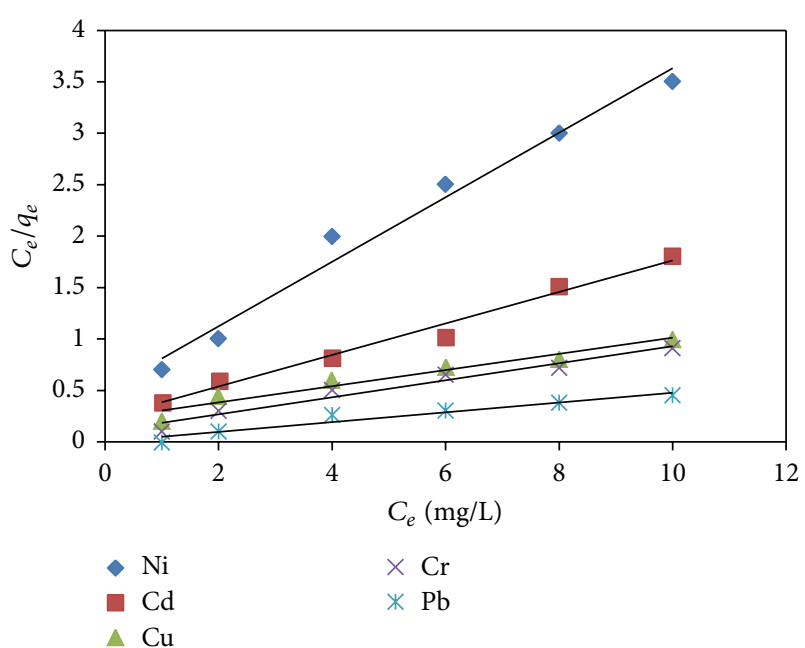

FIGURE 3: Langmuir isotherm showing the variation of adsorption $\left(C_{e} / q_{e}\right)$ against the equilibrium concentration $\left(C_{e}\right)$ for adsorption of metal ions onto ATS.

TABLE 2: Isotherm parameters for adsorption of metal ions onto ATS.

\begin{tabular}{lcccc}
\hline \multirow{2}{*}{ Isotherm model } & \multirow{2}{*}{ Metal ion } & \multicolumn{3}{c}{ Estimated isotherm parameters } \\
& & $q_{\max }(\mathrm{mg} / \mathrm{g})$ & $b(\mathrm{~L} / \mathrm{mg})$ & $R^{2}$ \\
\hline \multirow{4}{*}{ Langmuir } & $\mathrm{Ni}$ & 41.2 & 0.189 & 0.998 \\
& $\mathrm{Cu}$ & 34 & 0.173 & 0.982 \\
& $\mathrm{Cd}$ & 27.2 & 1.908 & 0.940 \\
& $\mathrm{Cr}$ & 21.3 & 0.143 & 0.962 \\
& $\mathrm{~Pb}$ & 17.5 & 0.114 & 0.945 \\
\hline \multirow{4}{*}{ Freundlich } & $\mathrm{Metal}$ ion & $n$ & $K_{f}$ & $R^{2}$ \\
\hline & $\mathrm{Ni}$ & 1.10 & 1.24 & 0.748 \\
& $\mathrm{Cd}$ & 2.11 & 3.52 & 0.977 \\
& $\mathrm{Cu}$ & 1.53 & 2.01 & 0.967 \\
& $\mathrm{Cr}$ & 1.50 & 1.77 & 0.939 \\
& $\mathrm{~Pb}$ & 1.51 & 1.82 & 0.957 \\
\hline
\end{tabular}

$\mathrm{pH} 1.0-11.0$, and the maximum removal capacity of ATS was found to be at $\mathrm{pH}$ 6.5. Percent metal ions removal increased rapidly with the increase in $\mathrm{pH}$ of the solution initially, and the optimal $\mathrm{pH}$ was observed at $\mathrm{pH}$ 6.5. Further increase in $\mathrm{pH}$ causes a drastic decrease in the adsorption percentage. This might be due to the weakening of electrostatic force of attraction between the oppositely charged adsorbate and adsorbent which ultimately leads to the reduction in sorption capacity [24].

3.6. Adsorption Isotherm. Adsorption is usually described through isotherms, that is, functions which connect the amount of adsorbate on the adsorbent. Distribution of metal ions between the liquid phase and the solid phase can be described by several isotherm models such as Langmuir and Freundlich. The Langmuir isotherm assumes monolayer adsorption onto a surface containing a finite number of adsorption sites of uniform strategies with no transmigration

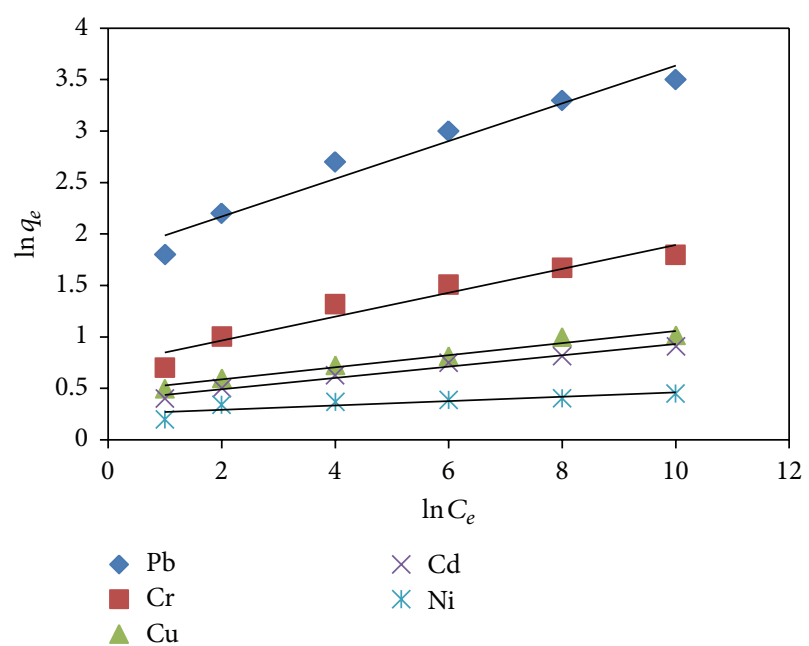

FIGURE 4: Freundlich isotherm representing variation of $\ln \left(q_{e}\right)$ with respect to $\ln \left(C_{e}\right)$ for adsorption of metal ions onto ATS.

of adsorbate in the plane surface [25]. Once a site is filled, no further sorption can take place at that site. This indicates that the surface reaches a saturation point where the maximum adsorption of the surface will be achieved. The isotherm is represented by

$$
\frac{C_{e}}{q_{e}}=\frac{1}{b q_{\max }}+\frac{C_{e}}{q_{\max }} .
$$

The linear plot of specific adsorption $\left(C_{e} / q_{e}\right)$ against the equilibrium concentration $\left(C_{e}\right)$ (Figure 3 ) shows that the adsorption obeys the Langmuir model. The constants $b$ and $q_{\max }$ relate to the energy of adsorption and maximum adsorption capacity, and their values are obtained from the slope and interception of the plot and are presented in Table 2.

The Freundlich isotherm is introduced as an empirical model, where $q_{e}$ represents the amount adsorbed per amount of adsorbent at the equilibrium $(\mathrm{mg} / \mathrm{g}), C_{e}$ represents the equilibrium concentration $(\mathrm{mg} / \mathrm{L})$, and $K_{f}$ and $n$ are parameters that depend on the adsorbate and adsorbent.

Consider

$$
q_{e}=K_{f} C_{e}^{1 / n} .
$$

The equation can be linearized and the temperature dependent constants $K_{f}$ and $1 / n$ found by linear regression:

$$
\ln q_{e}=\ln K_{f}-\frac{1}{n} \ln C_{e},
$$

where $K_{f}$ and $n$ are Freundlich constants which correspond to adsorption capacity and adsorption intensity, respectively. Freundlich equilibrium constants were determined from the plot of $\ln q_{e}$ versus $\ln C_{e}$ from Figure 4, on the basis of the linear form of Freundlich equation. The $n$ value indicates the degree of nonlinearity between solution concentration and adsorption as follows: if $n=1$, then adsorption is linear; if $n<1$, then adsorption is a chemical process; if $n>1$, then adsorption is a physical process. The $n$ value in Freundlich 
equation was found to be 1.10-2.11, (Table 2). The situation $n>1$ is most common and may be due to a distribution of surface sites or any factor that causes a decrease in adsorbentadsorbate interaction with increasing surface density [26] and the values of $n$ within the range of 1-10 represent good adsorption $[27,28]$. In the present study, since $n$ lies between 1 and 10 it indicates the physical adsorption of metal ions onto ATS.

In both cases, linear plots were obtained, which reveal the applicability of these isotherms on the ongoing adsorption process. Figures 3 and 4 exhibit Langmuir and Freundlich plots, respectively, for the adsorption of metal ions onto ATS, and different Langmuir and Freundlich constants derived from these plots are presented in Table 2. Nearly similar results have been reported in the literature [29-31] for Langmuir and Freundlich models.

Langmuir and Freundlich adsorption constants and correlation coefficients $\left(R^{2}\right)$ are presented in Table 2. To find the most appropriate model for the metal ions adsorption; data were fitted to Langmuir and Freundlich isotherm models. Results revealed that Langmuir adsorption isotherm was the best model for the metal ions adsorption onto ATS with $R^{2}$ of 0.998 . The essential features of Langmuir adsorption isotherm parameter can be used to predict the affinity between the sorbate and sorbent using a dimensionless constant called separation factor or equilibrium parameter $\left(R_{L}\right)$, which is expressed by the following relationship $[32,33]$ :

$$
R_{L}=\frac{1}{\left(1+b C_{i}\right)}
$$

where $b$ is the Langmuir constant and $C_{i}$ is the initial concentration. The value of $R_{L}$ indicated the type of Langmuir isotherm to be irreversible $\left(R_{L}=0\right)$, linear $\left(R_{L}=1\right)$, unfavorable $\left(R_{L}>1\right)$, or favorable $\left(0<R_{L}<1\right)$ [34]. The $R_{L}$ values between 0 and 1 indicate favorable adsorption. The $R_{L}$ value in the present investigation was found to be $0.298-$ 0.986 , indicating that the adsorption of the metal ion onto ATS is favorable.

\section{Conclusions}

Teff (Eragrostis tef) straw is environment friendly, costeffective, and locally available agrowaste adsorbent for the adsorption of metal ions from textile effluents. Results from this study showed that adsorption of heavy metals onto ATS increases with the amount of adsorbent. This may be explained because of the fact that adsorption is a surface phenomenon where adsorbate molecules occupy specific sites on the adsorbent. These sites are commonly known as active centers. The concentration of these active centers on the surface is further related to the pore size and pore volume available after impregnation. This explains why increasing the quantity of adsorbent results in increased adsorption. Results revealed that initially the \% removal increase, rapidly; however, after some times the rate becomes almost constant. This is because all the available active centers on the adsorbent have been occupied and there are no further sites and hence no further adsorption is possible. The time when this phenomenon occurs, therefore, may be termed optimum time.

The adsorption isotherms could well be fitted by the Langmuir model. The $R_{L}$ value in the present investigation was less than one, indicating that the adsorption of the metal ion onto ATS is favorable. In treatment with ATS, the removal of metal ions from textile wastewater sample is high whereby the percentage of removal is more than 80 percent of the initial concentration. Since Teff Straw is freely abundant, locally available, low-cost adsorbent and has a considerable high adsorption capacity, it may be treated as economically viable for removal of metal ions from textile effluents.

\section{Acknowledgments}

This study was done in the Department of Chemistry, Mekelle University, Ethiopia. The author is grateful to Dr. Abraha G/Kidan for providing column adsorption apparatus. The author would like to thank Mr. Mehari (the factory manager), Mr. Amanuel (textile engineer), and Mr. Mesfin (treatment plant supervisor) for providing the necessary facilities to carry out this work.

\section{References}

[1] N. Mathur, P. Bhatnagar, and P. Bakre, "Assessing mutagenicity of textile dyes from pali (Rajasthan) using ames bioassay," Applied Ecology and Environmental Research, vol. 4, no. 1, pp. 111-118, 2006.

[2] P. U. Singare, R. S. Lokhande, and K. U. Naik, "A case study of some lakes located at and around thane city of Maharashtra, India, with special reference to physico-chemical properties and heavy metal content of lake water," Interdisciplinary Environmental Review, vol. 11, no. 1, pp. 90-107, 2010.

[3] J. O. Esalah, M. E. Weber, and J. H. Vera, "Removal of lead, cadmium and zinc from aqueous solutions by precipitation with sodium di-(n-octyl) phosphinate," Canadian Journal of Chemical Engineering, vol. 78, no. 5, pp. 948-954, 2000.

[4] A. I. Zouboulis, K. A. Matis, B. G. Lanara, and C. L. Neskovic, "Removal of cadmium from dilute solutions by hydroxy apatite. II. floatation studies," Separation Science and Technology, vol. 32, no. 10, pp. 1755-1767, 1997.

[5] A. I. Zouboulis, K. A. Matis, B. G. Lanara, and C. L. Neskovic, "Removal of cadmium from dilute solutions by hydroxy apatite. II: floatation studies," in The Protocols, K. R. Fall and W. R. Stevens, Eds., vol. 1 of TCP/IP Illustrated, Addison-Wesley, Reading, Mass, USA, 2nd edition, 2011.

[6] L. Canet, M. Ilpide, and P. Seta, "Efficient facilitated transport of lead, cadmium, zinc, and silver across a flat-sheet-supported liquid membrane mediated by lasalocid A," Separation Science and Technology, vol. 37, no. 8, pp. 1851-1860, 2002.

[7] K. Dermentiz, A. Christoforidis, E. Valsamidou, A. Loucas, and K. Greece, "Removal of nickel, copper, zinc and chromium from synthetic and industrial wastewater by electrocoagulation," International Journal of Environmental Sciences, vol. 1, no. 5, pp. 697-710, 2011.

[8] V. J. Inglezakis, M. D. Loizidou, and H. P. Grigoropoulou, "Ion exchange of $\mathrm{Pb}^{2+}, \mathrm{Cu}^{2+}, \mathrm{Fe}^{3+}$, and $\mathrm{Cr}^{3+}$ on natural clinoptilolite: selectivity determination and influence of acidity on metal uptake," Journal of Colloid and Interface Science, vol. 261, no. 1, pp. 49-54, 2003. 
[9] P. T. Bolger and D. C. Szlag, "Electrochemical treatment and reuse of nickel plating rinse waters," Environmental Progress, vol. 21, no. 3, pp. 203-208, 2002.

[10] K. Dermentzis, "Removal of nickel from electroplating rinse waters using electrostatic shielding electrodialysis/electrodeionization," Journal of Hazardous Materials, vol. 173, no. 1-3, pp. 647-652, 2010.

[11] M. A. Amer, F. I. Khaili, and A. M. Awwad, "Adsorption of lead, zinc and cadmium ions on polyphosphate-modified kaolinite clay," Journal of Environmental Chemistry and Ecotoxicology, vol. 2, no. 1, pp. 1-8, 2010.

[12] N. O. Reuben and J. A. Miebaka, "Chromium (VI) adsorption rate in the treatment of liquid phase oil based drill cuttings," African Journal of Environmental Science and Technology, vol. 2, no. 4, pp. 68-674, 2008.

[13] R. Ahmed, T. Yamin, M. S. Ansari, and S. M. Hasany, "Sorption behaviour of lead(II) ions from aqueous solution onto Haro river sand," Adsorption Science and Technology, vol. 24, no. 6, pp. 475-486, 2006.

[14] D. F. Aloko and E. A. Afolabi, "Titanium dioxide as a cathode material in a dry cell," Leonardo Electronics Journal of Practices and Technologies, vol. 11, pp. 97-108, 2007.

[15] D. F. Aloko and E. A. Afolabi, "Model development of the adsorption of cations on manganese dioxide $\left(\mathrm{MnO}_{2}\right)$ used in a Leclanche dry cell," Leonardo Journal of Sciences, vol. 8, pp. 13-20, 2006.

[16] C. C. Chen and Y. C. Chung, "Arsenic removal using a biopolymer chitosan sorbent," Journal of Environmental Science and Health - Part A Toxic/Hazardous Substances and Environmental Engineering, vol. 41, no. 4, pp. 645-658, 2006.

[17] N. Amin, S. Kaneco, T. Kitagawa et al., "Removal of arsenic in aqueous solutions by adsorption onto waste rice husk," Industrial and Engineering Chemistry Research, vol. 45, no. 24, pp. 8105-8110, 2006.

[18] A. M. M. Khaled, A Comparative study for distribution of some heavy metals in aquatic organisms fished from Alexandria region [Ph.D. thesis], Chemistry Department, Faculty of Science, Alexandria University, Alexandria, Egypt, 1998.

[19] K. Steve, T. Erika, T. Reynold, and M. Paul, "Activated carbon: a unit operations and processes of activated carbon," in Environmental Engineering, vol. 25, pp. 350-749, PWS Publishing, 2nd edition, 1998.

[20] C. Ng, J. N. Losso, W. E. Marshall, and R. M. Rao, "Freundlich adsorption isotherms of agricultural by-product-based powdered activated carbons in a geosmin-water system," Bioresource Technology, vol. 85, no. 2, pp. 131-135, 2002.

[21] B. M. G. Jones, J. Ponti, A. Tavassoli, and P. A. Dixon, "Relationships of the ethiopian cereal t'ef (Eragrostis tef (Zucc.) Trotter): evidence from morphology and chromosome number," Annals of Botany, vol. 42, no. 6, pp. 1369-1373, 1978.

[22] S. H. Costanza, J. M. J. Dewet, and J. R. Harlan, "Literature review and numerical taxonomy of Eragrostis tef (T'ef)," Economic Botany, vol. 33, no. 4, pp. 413-424, 1979.

[23] E. Bekele and R. N. Lester, "Biochemical assessment of the relationships of Eragrostis tef (Zucc.) trotter with some wild Eragrostis species (Gramineae)," Annals of Botany, vol. 48, no. 5, pp. 717-725, 1981.

[24] S. S. Baral, S. N. Das, and P. Rath, "Hexavalent chromium removal from aqueous solution by adsorption on treated sawdust," Biochemical Engineering Journal, vol. 31, no. 3, pp. 216222, 2006.
[25] B. H. Hameed, A. T. M. Din, and A. L. Ahmad, "Adsorption of methylene blue onto bamboo-based activated carbon: kinetics and equilibrium studies," Journal of Hazardous Materials, vol. 141, no. 3, pp. 819-825, 2007.

[26] B. E. Reed and M. R. Matsumoto, "Modeling cadmium adsorption by activated carbon using the Langmuir and Freundlich isotherm expressions," Separation Science and Technology, vol. 28, no. 13-14, pp. 2179-2195, 1993.

[27] G. McKay, M. S. Otterburn, and A. G. Sweeney, "The removal of colour from effluent using various adsorbents. III. Silica: rate processes," Water Research, vol. 14, no. 1, pp. 15-20, 1980.

[28] A. Özer and H. B. Pirinççi, "The adsorption of Cd(II) ions on sulphuric acid-treated wheat bran," Journal of Hazardous Materials, vol. 137, no. 2, pp. 849-855, 2006.

[29] A. Mittal, L. Kurup, and J. Mittal, "Freundlich and Langmuir adsorption isotherms and kinetics for the removal of Tartrazine from aqueous solutions using hen feathers," Journal of Hazardous Materials, vol. 146, no. 1-2, pp. 243-248, 2007.

[30] M. Malakootian, J. Nouri, and H. Hossaini, "Removal of heavy metals from paint industry's wastewater using Leca as an available adsorbent," International Journal of Environmental Science and Technology, vol. 6, no. 2, pp. 183-190, 2009.

[31] H. Liu, Y. Dong, H. Wang, and Y. Liu, "Adsorption behavior of ammonium by a bioadsorbent-Boston ivy leaf powder," Journal of Environmental Sciences, vol. 22, no. 10, pp. 1513-1518, 2010.

[32] K. R. Hall, L. C. Eagleton, A. Acrivos, and T. Vermeulen, "Pore- and solid-diffusion kinetics in fixed-bed adsorption under constant-pattern conditions," Industrial and Engineering Chemistry Fundamentals, vol. 5, no. 2, pp. 212-223, 1966.

[33] P. K. Malik, "Dye removal from wastewater using activated carbon developed from sawdust: adsorption equilibrium and kinetics," Journal of Hazardous Materials, vol. 113, no. 1-3, pp. 81-88, 2004.

[34] G. McKay, H. S. Blair, and J. R. Gardner, "Adsorption of dyes on chitin," Journal of Applied Polymer Science, vol. 27, no. 8, pp. 3043-3057, 1982. 

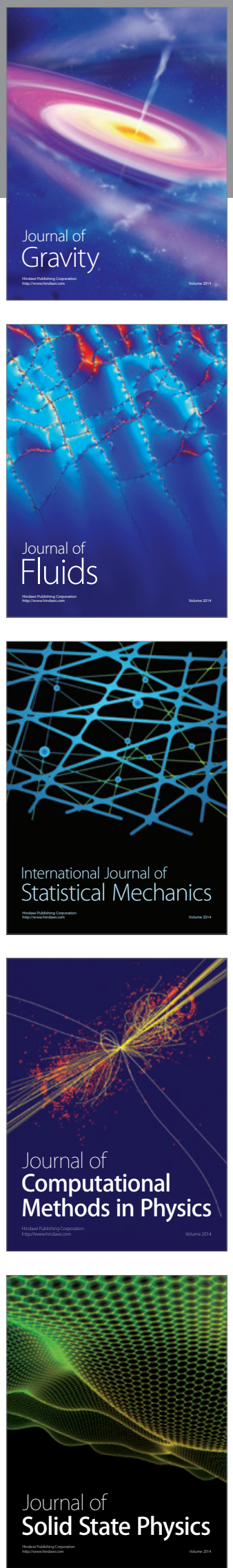

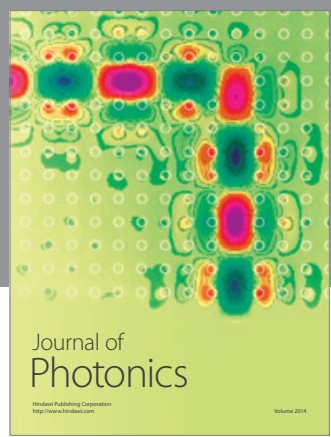

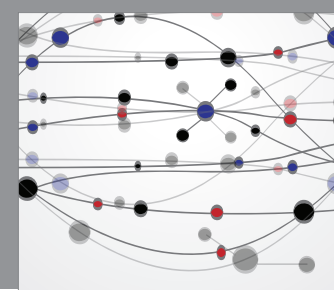

The Scientific World Journal

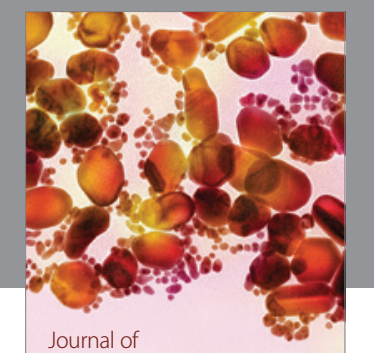

Soft Matter
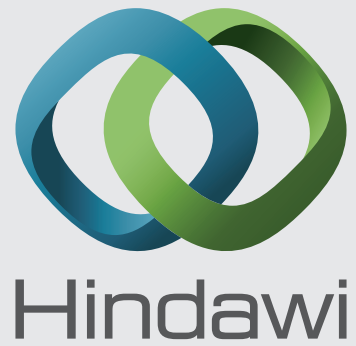

Submit your manuscripts at

http://www.hindawi.com
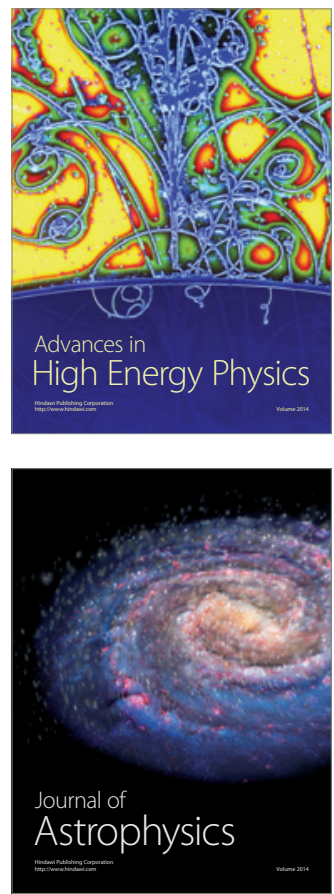
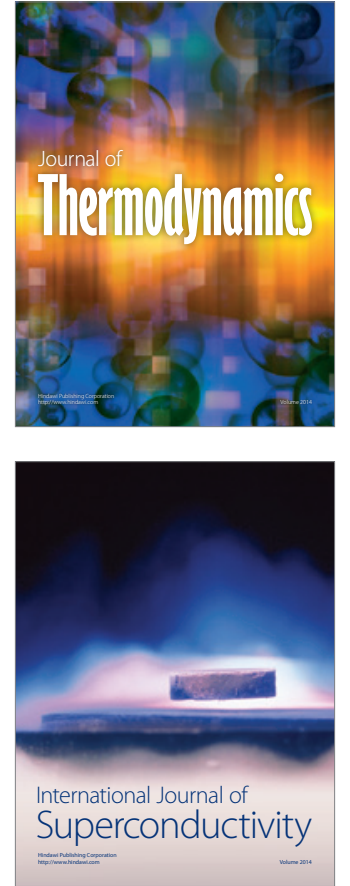
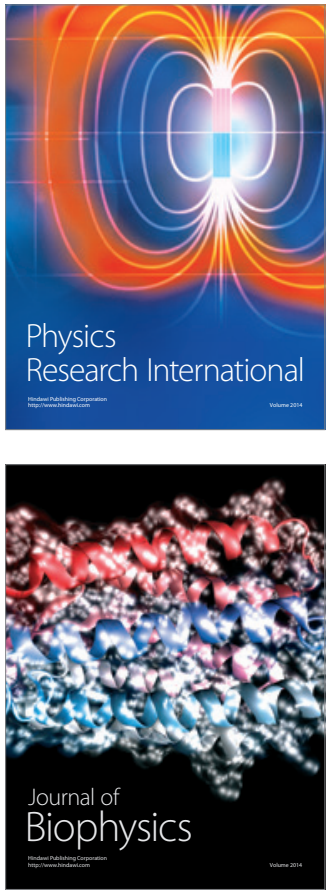
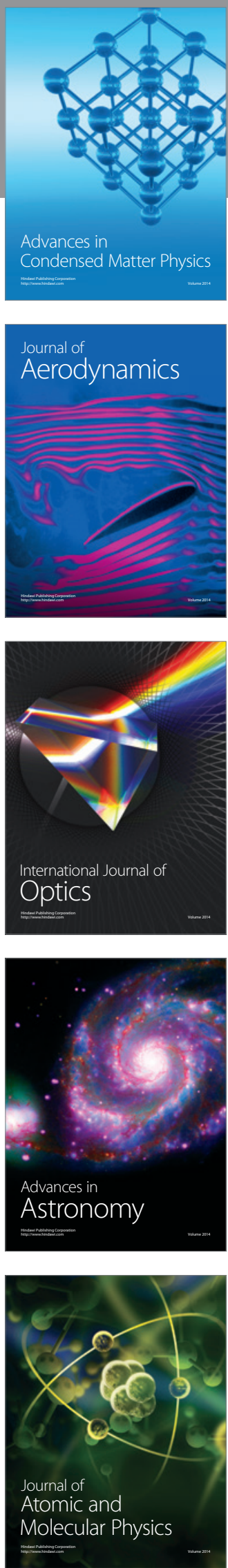